Article

\title{
Mediated by Code: Unpacking Algorithmic Curation of Urban Experiences
}

\author{
Annelien Smets *, Pieter Ballon and Nils Walravens \\ imec-SMIT, Vrije Universiteit Brussel, Belgium; E-Mails: annelien.smets@vub.be (A.S.), pieter.ballon@vub.be (P.B.), \\ nils.walravens@imec.be (N.W.) \\ * Corresponding author
}

Submitted: 29 January 2021 | Accepted: 24 April 2021 | Published: 18 November 2021

\begin{abstract}
Amid the widespread diffusion of digital communication technologies, our cities are at a critical juncture as these technologies are entering all aspects of urban life. Data-driven technologies help citizens to navigate the city, find friends, or discover new places. While these technology-mediated activities come in scope of scholarly research, we lack an understanding of the underlying curation mechanisms that select and present the particular information citizens are exposed to. Nevertheless, such an understanding is crucial to deal with the risk of the socio-cultural polarization assumedly reinforced by this kind of algorithmic curation. Drawing upon the vast amount of work on algorithmic curation in online platforms, we construct an analytical lens that is applied to the urban environment to establish an understanding of algorithmic curation of urban experiences. In this way, this article demonstrates that cities could be considered as a new materiality of curational platforms. Our framework outlines the various urban information flows, curation logics, and stakeholders involved. This work contributes to the current state of the art by bridging the gap between online and offline algorithmic curation and by providing a novel conceptual framework to study this timely topic.
\end{abstract}

\section{Keywords}

algorithmic curation; algorithmic mediators; context media; smart cities; spatiality; urban algorithms

\section{Issue}

This article is part of the issue "Algorithmic Systems in the Digital Society" edited by Sanne Kruikemeier (University of Amsterdam, The Netherlands), Sophie Boerman (University of Amsterdam, The Netherlands), and Nadine Bol (Tilburg University, The Netherlands).

(C) 2021 by the authors; licensee Cogitatio (Lisbon, Portugal). This article is licensed under a Creative Commons Attribution 4.0 International License (CC BY).

\section{Introduction}

The pervasiveness of digital communication technologies in our urban environments results in large amounts of data. These high volumes of data not only provide the means to monitor particular aspects of urban life, such as air quality or traffic; they also increasingly subject it to mediation by code (Amin \& Thrift, 2002). Technologymediated activities, in so-called smart cities, are indeed (re)producing urban spatiality (Ballon \& Smets, 2021; Ridell \& Zeller, 2013): citizens use digital applications to discover new destinations (e.g., Tripadvisor), places to eat or rest (e.g., Airbnb), or navigate the urban environment (e.g., Waze). Mediation, however, inherently comes with curation. While mediation refers to the organizational structure of an intermediary in between mul- tiple actors, curation deals with the specific activity of selecting and presenting the information through the intermediary (Rader \& Gray, 2015). Currently, this type of curational activities of digital intermediaries is a contentious topic among media and communication scholars. This line of research focuses on the curational role of algorithms in online platforms, such as Facebook or Twitter, and their ability to shape how we see, experience, and understand the world (Bucher, 2018; Kitchin \& Dodge, 2011; Willson, 2017).

The intensified mediation through data-driven urban technologies, however, results in the curational practices of algorithms no longer being limited to the mere online world (Foth, 2017). The ubiquity of these technologies is reconfiguring time-space relationships and consequently citizens' relation with the city and each 
other, both online and offline. This raises fundamental questions as to what extent the urban space can still fulfill its role as public space and facilitate social encounters (McQuire, 2016). Therefore, the question of how we experience the urban space is more than a trivial question; it relates to the degree in which we interact with others and experience unpredictable encounters, which has been considered essential to foster necessary skills for cosmopolitan civility (Jacobs, 1961; Sennett, 1978). It is therefore crucial to understand how the use of algorithms and their curational practices could change our urban experience, both from an individual and societal point of view. What are the consequences of citizens' exposure to these algorithms? Can they exclude people from particular public places? Are citizens prone to end up in so-called "urban filter bubbles" (Smets et al., 2019)? These are some of the many questions that illustrate that urban algorithms should be subject of critical research as well (Foth, 2017; Graham, 2005). While the intersection of urbanism and digital technologies (e.g., algorithms) is typically in scope of the smart city discourse, to the best of our knowledge, little attention has been paid to the curational role of algorithms in this field. At the same time, the current study of algorithmic curation itself is mainly grounded in traditional communication studies and lacks a foundation that takes into account the specific nature of the urban context (Foth, 2017). This work sets out to address this shortcoming and develop a framework to organize the research of algorithmic curation of urban experiences. Drawing upon the vast amount of work of algorithmic curation in online platforms, we construct an analytical lens that is subsequently translated to the urban environment, in order to establish our framework on algorithmic curation of urban experiences.

\section{Methodological Approach}

The aim of this work is to unpack algorithmic curation of urban experiences. In other words, to provide an analytical framework that can be used to guide the study of algorithmic curation of urban experiences. In the last decade, media and communication scholars increasingly started to discuss algorithmic curation in online platforms, such as Facebook or Google Search (e.g., Rader, 2017; Trielli \& Diakopoulos, 2019). While it is clear that we cannot simply apply their understanding of algorithmic curation to the physical urban environment (Foth, 2017), we can draw some important insights from these works and use it to develop an analytical perspective that can be applied to the urban context. After all, this intensified mediation through data-driven urban technologies can simply be considered as a new materiality of curational platforms: context media. Thanks to the affordances provided by new technologies (e.g., location services, sensing capabilities, etc.), platforms such as Waze or Uber are able to tailor their services towards an individual context. These services are not only taking into account one's individual preferences, but also increasingly rely on additional information such as what you are doing, where you are, and what that particular context looks like. An example is Uber's controversial technique of "surge pricing" where cab fares depend on contextual factors such as weather or traffic conditions (Guda \& Subramanian, 2019). This notion of context media has been described in literature using different terminologies, such as "locative" or "urban" media (de Waal, 2013). However, this relationship and (dis)similarities with algorithmic curation in merely online platforms has remained largely unexplored.

This work mainly draws upon a literature review that has been conducted using Google Scholar as research database. Google Scholar is known to have a broad reach in terms of disciplines; however, this broadness is also a challenge in terms of volume (Martín-Martín et al., 2018). We therefore only included English peerreviewed articles, from both journals and conferences, and academic book sections. To select the search terms for our literature study, we started from the key concepts of our research scope (cities, algorithmic curation, and experiences), and, for each of these concepts, we constructed a list of related terms (e.g., urban space[s], smart city, algorithmic shaping, citizen experience[s]). These search terms were then combined in such a way that our search results would represent the intersection of the three key concepts. This was a challenging exercise: Some combinations did not result in any (or very few) results, whereas others resulted in an explosion in terms of retrieved documents (over 10 thousand results). We learned that the particular combination of "algorithmic curation" and "urban experiences" was a constraining factor, which strengthens the hypothesis that algorithmic curation of urban experiences has rarely been discussed. Consequently, we had to find the balance between sensitivity and specificity. We decided to relax our search conditions in two ways. First, we only combined search terms related to "city" and "algorithmic curation" and collected those results. Second, we combined the three key concepts but no longer used the particular wording of "algorithmic curation" and relaxed the search term to "algorithm" instead. In what follows we will refer to these searches as Search 1 (city + algorithmic curation) and Search 2 (city + algorithm + citizen experiences). This literature review was performed in December 2019. Search 1 resulted in a final selection of 65 articles, based on the abovementioned criteria, accessibility, and relevance for our work. Interestingly, although search terms related to "city" were explicitly mentioned, none of these articles actually dealt with algorithmic curation in urban environments. The majority of these studies discuss algorithmic curation in online (social) media environments, such as platforms like Facebook or Twitter. The articles were nonetheless highly relevant as they were the basis to develop our understanding of algorithmic curation in general (cf. Section 3). Search 2, on the other hand, 
resulted in articles that were very much centered on cities and urban contexts. However, since we searched for "algorithms" instead of "algorithmic curation" most of the articles discussed algorithms from a rather technical point of view. More specifically, from the 71 articles that matched our above-mentioned criteria, another 60 items were excluded because their content did not match our research scope at all. The remaining 11 articles were used to construct the analytical framework for the urban context (cf. Section 4).

In the remainder of this work, we will address our research question about how algorithmic curation of urban experiences can be studied. We will first elaborate on the notion of algorithmic curation (based on results from Search 1 and develop an understanding of the building blocks that we consider to be core of its study. Subsequently, we will translate these building blocks to the urban scene and elaborate them based on the literature in our review (results from Search 2) and complement them with examples known by the authors. Following this, we present an integrative approach to study algorithmic curation of urban experiences and discuss how this can be put into practice.

\section{Studying Algorithmic Curation}

By analyzing the literature that deals with algorithmic curation we identify four main constructs to guide its study: information flows, feedback loops, curation logics, and multi-stakeholder configurations.

\subsection{Information Flows and Feedback Loops}

Algorithmic curation is most commonly defined as "organizing, selecting, and presenting subsets of a corpus of information for consumption" (Rader \& Gray, 2015, p. 1). Many authors indeed refer to particular mechanisms that influence particular flows of information, such as selecting, organizing, filtering, prioritizing, classifying, and associating (Eslami et al., 2015; Liu, 2010, 2012; Prado, 2014; Rader \& Gray, 2015; Shapiro \& Hall, 2018; Thorson \& Wells, 2015b). In this stream of thought, the algorithm is thus considered to be (part of) a digital information intermediary. Algorithmic curation is therefore often associated with gatekeeping: "The process of culling and crafting countless bits of information into the limited number of messages that reach people each day" (Shoemaker \& Vos, 2009, p. 1). However, whereas traditional gatekeeping theories emphasize the negating role of such processes (Thorson \& Wells, 2015a), the notion of curation rather stresses the idea of promoting content (Swords, 2017). In this sense, curation is more appropriate for our contemporary media environments characterized by information overload and attention scarcity (Thorson \& Wells, 2015a). An intermediary having this gatekeeping (or curational) power has "a major lever in the control of society" (Bagdikian, 1983, p. 226) and therefore scholars plea for a system- atic way to analyze the gatekeeping functions of algorithmic curation, so-called "algorithmic audits" (Bandy \& Diakopoulos, 2019; Sandvig et al., 2014).

Despite the opaqueness of algorithms ("black boxes"), people seem to develop strategies to game the algorithm. Even though they do not know how the algorithm works, by experimenting with it and adapting their behavior, they develop strategies to make use of the algorithm in their own favor (Bucher, 2017; Eslami et al., 2016). As put by Rader and Gray (2015): “They adapt their behavior to correspond with how they believe the system works, in order to accomplish their goals for using the system" (p. 8). Some users, for example, claim to use another computer to prevent ending up in a "filter bubble" (Bilandzic et al., 2018). Napoli (2018) even talks about an entire industry that "has arisen around optimizing content for social media curation algorithms" (p. 8). This means that there is an (unconscious) response to the feedback loop characteristics of these systems. These feedback loops are hence an important factor in shaping the overall system behavior and should therefore be considered in the analysis of algorithmic curation (Rader \& Gray, 2015).

\subsection{Curation Logics and Multi-Stakeholder Configurations}

Such analysis should not be limited to the algorithm itself. Scholars like Kitchin (2017b) and Seaver (2019) call for the study of algorithms in their "full socio-technical assemblage" which requires an assessment including all actors. Indeed, algorithms do not originate from a void and they should be examined as sociotechnical constructs influenced by their context of creation and use (Seaver, 2019). Grounding in the literature concerned with information flows in media environments, Thorson and Wells (2015a) argue that different curating actors do not exist next to each other and rather show a significant degree of overlap or intersection. They call for an empirical investigation of the extent to which these interactions occur, with particular attention to the "curation logics" of these actors. These logics refer to the "particular interests, norms, incentives and network positions" that play an essential role in the decision about which content to present (Thorson \& Wells, 2015a, p. 5). The identification of these curation logics is argued to be "useful to structure theory and guide empirical research" (Landerer, 2013, p. 248).

The importance of the curation logics of multiple actors refers to the multi-sidedness of algorithmic curation. In the literature, we observe three stands of research each discussing a different side: (1) End-usersexamining how algorithmic curation influences users' content exposure on social media (Bandy \& Diakopoulos, 2019; Diakopoulos, 2015; Nelimarkka et al., 2018; Rader, 2017; Yatid, 2019), their exposure to diverse news (Ku et al., 2019; Wohn \& Bowe, 2016) or fake news (Cohen, 2018), or users' feelings and beliefs about the 
algorithmic curation (Bucher, 2017; Eslami et al., 2015, 2016; Rader \& Gray, 2015); (2) providers-studying the actor who provides the information that is curated, such as journalists who create online news content (Usher, 2017); (3) operators-examining the algorithm and its operator, for example Bernal's (2018) discussion on how Facebook's business model makes the fake news problem inevitable.

Summarizing, the study of algorithmic curation should be guided by the following questions: What information flows are being curated? Which feedback loops can be identified? Who are the different stakeholders involved? What are their curation logics? However, in order to apply this to the urban context we need to be able to identify the algorithmic mediators that curate the information and eventually understand how these relate to one another, as well as the urban experience itself.

\section{Setting the Urban Scene}

So far, we mainly discussed curation in online platforms such as Facebook. However, the premise of this work is that a new materiality of curational platforms arises: the urban scene. There is indeed a growing line of work that focusses on the spatiality of media such as Foursquare, Pokémon Go, or Waze. However, the personal applications that people use in their everyday life are not the sole algorithmic mediators in the urban sphere. Indeed, the last decade has been characterized by cities increasingly implementing digital technologies, both in the public environment and public services (Ballon \& Smets, 2021). The main difference between purely online platforms such as Facebook and those that operate at the intersection of offline and online, is their ubiquity. As a consequence, the identification of these mediators and the information flows they curate is particularly challenging. Before addressing this, we start with a brief discussion of the essential building blocks of information-data.

\subsection{Urban Data Landscape}

When discussing data in an urban setting, most people think of "urban operational data" generated by sensors monitoring air quality or cameras counting road traffic. However, there are many other data sources contributing to the urban data landscape (Kitchin, 2017a). Mobile phone operators generate data about people's location; and social media and websites such as TripAdvisor or Airbnb generate data that to a large extent reflect personal experiences of citizens (photos, reviews, likes, etc.; Cervantes et al., 2016; Foth et al., 2011). Another category of "data providers" are organizations such as financial institutions or retail chains that generate data on financial transactions and purchases. All of these companies and platforms are increasingly making their data publicly available through API's or sell them through data brokers (Kitchin, 2017a). Another emergent type of data source is crowdsourcing or citizen science. Here, citizens actively contribute to data collections (e.g., Open Street Map) or even install their own data collection infrastructure to collect data about their neighborhood. The distinctive feature of most of this data (and related technologies) is their velocity, or real time character (Kitchin, 2014). This enables a wide range of curational activities that require algorithmic mediators that can analyze and act upon this data simultaneously. Perhaps the most common example is traffic, where real time data from various sources is used to fuel personal navigation applications such as Waze. However, other more innovative scenarios exist where such real time data is used to physically alter the urban infrastructure. For example, by means of changing the function of a particular zone (e.g., vehicles vs. pedestrians). The remainder of this section is set out to identify those different types of algorithmic mediators and discuss their multi-stakeholder configurations.

\subsection{Urban Information Flows}

Following our understanding of algorithmic curation developed in the previous section, we first need to identify digital intermediaries in cities in order to analyze the algorithmically curated urban information flows. Drawing from case descriptions discussing data-driven urban technologies, we identify two main categories of urban mediators that will be core in our conceptual framework: networked people and urban infrastructure (Figure 1).

\subsubsection{Networked People}

This category represents digital services that citizens directly interact with. Indeed, in contemporary cities, citizens are participating members of a greater collective and technology aims to strengthen this connectedness among citizens as well as their environment (Foth et al., 2011). In this sense, citizens are increasingly networked people. This category consists of personal applications such as smartphone applications or websites. For example, a smartphone application providing personalized recommendations to tourists about points of interest in a particular area (Cervantes et al., 2016). The navigation application Waze is another exemplary case of how people use digital interfaces to consult information and generate knowledge about their urban environment. In this case, the application is often no longer a mere information intermediary, but also acts as an actual guide through the roads with the least traffic. Personal applications can also be used to connect with other people in the environment. Citysocializer is such an application that aims to facilitate meeting new people and making friends in your own city by attending social events. Apart from applications and services to meet new people, popular applications like Facebook, Yelp, or Find My (Friends) also allow users to share their location with their friends. 


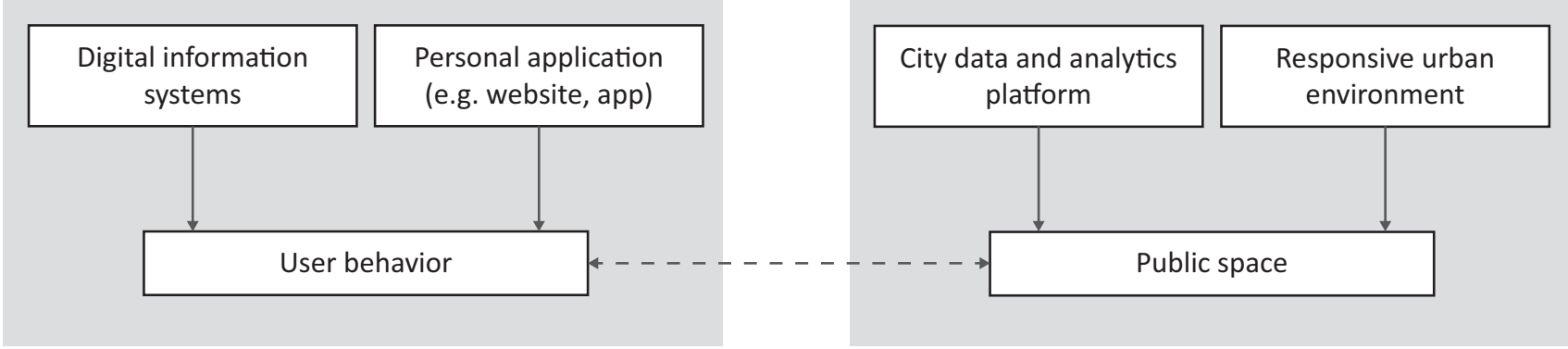

Figure 1. Identified algorithmic mediators in the urban context, and their impact on user behavior and the public space.

Another type of application in this category are community platforms such as Nextdoor or Hoplr. These applications are oriented towards community building and bringing together people from the same neighborhood by facilitating the exchange of information or goods. By establishing this sense of community, these platforms also aim to enhance the overall experience of a particular neighborhood (De Meulenaere et al., 2020). Apart from personal applications, we also distinguish more generally available digital information systems, such as digital signage that can be found on city squares. Citizens can consult these systems to gather information about the environment, such as information on upcoming events or an overview of pleasant walking routes in the area (Koto \& Bandung, 2016).

Each of these services thus mediates information and, in this way, also inevitably engages in curational practices by deciding which information to filter, select, or present. Similar to the Facebook algorithm deciding which friends most frequently pop up on your newsfeed, the Citysocializer algorithm could greatly influence your new group of friends by recommending particular types of events. The information that is curated by these intermediaries could greatly affect citizens behavior, for example by suggesting where to go. Therefore, we assemble the impact of these curated information flows in the notion of user behavior, the collection of actions undertaken by citizens. The latter represents a crucial connection to the physical public space, as will become evident in the following sections.

\subsubsection{Urban Infrastructure}

The urban infrastructure represents a second category of technologies that mediate the urban experience. The main difference with the previous category is the level of human agency. In the category of networked people, citizens have to take the initiative to consult information, i.e., they "pull" information. Contrary, the information that is mediated by the urban infrastructure is rather "pushed" upon the citizen. This category of mediators thus acts independently from any user interaction. Although an in-depth discussion goes beyond the scope of this article, this distinction has far-reaching conse- quences, not in the least for the degree to which citizens can control the algorithmic curation they are subjected to or to what extent they can develop the skills to cope with it.

We identify two types of intermediaries in this category: (1) city data and analytics platforms, and (2) responsive urban environments. The former refers to algorithmbased decision-support systems, such as dashboards or knowledge discovery tools that can inform city administrations about changes to the urban infrastructure (Al Nuaimi et al., 2015; Foth et al., 2011; Hanzl et al., 2012; Lim et al., 2018; Mora et al., 2017). This could be, for example, a citizen experience dashboard that "allows public administrations to understand the real expectations of the citizens to optimize investments or even predict the potential impact on citizens when redesigning the services" (Abella et al., 2017, p. 51). These dashboards are driven by data on citizens' experiences that could be provided directly (e.g., through surveys) or collected indirectly (e.g., posts on social media). Changes to the urban infrastructure could relate to public services such as public transport but also to urban planning and city infrastructure. An example are so-called "urban digital twins" (Mohammadi \& Taylor, 2017): (real-time) spatiotemporal data-driven models of the city that allow policy makers to rely on predictive modelling techniques to study the impact of a particular change to the urban infrastructure. Such a digital twin can be used to predict what happens to the air quality when a particular area would be turned into a pedestrian zone. This kind of city data and analytics platforms thus enable city administrations to make informed decisions about possible changes to the urban infrastructure, both public services and the public space.

A responsive urban environment, on the other hand, refers to an element of the physical urban space that is capable of acting upon data and adapting itself to it. A digital advertisement that adapts to the emotions of passers-by, and thereby eventually influences their experience, for example. This kind of technology is able to capture people's emotions and react to it, so-called "emphatic media" (McStay, 2016). The latter differs from the digital signage described in the previous section, as this one adapts itself regardless of any user interaction. 
Another example of urban responsiveness is illustrated by adaptive street environments: "the morphological transformation of the urban space enabled by smart sensors and responsive materials for adaptive options" (Andreani et al., 2019, p. 18). An example could be dynamic adjustments of traffic lanes with respect to vehicle flows or increasing presence of bikers and pedestrians, or adaptive traffic lights based on the actual traffic demand.

\subsubsection{Interaction Effect}

Finally, we want to address the missing link in the discussion so far: the relationship between networked people and the urban infrastructure. As said before, we consider public space to be constantly (re)produced through human activities (cf. the dotted line in Figure 1). Consequently, it is important to take into account how algorithmic curation could play a role in this relationship. For example, in our exemplary case of Waze, evidence shows that the use of Waze increases the traffic flow in smaller streets, which are often only designed for local traffic (Fisher, 2020; Macfarlane, 2019). As a consequence, these small streets suffer from the increasing volume of through traffic, e.g., resulting in increased congestion or accelerated deterioration of the road surface. This means that even when citizens do not use Waze themselves, their urban experience could be influenced by others who do. At this particular intersection of individual user behavior and the public space, the identification of conflicting interests among various actors is most emergent.

\subsection{Urban Curation Logics and Multi-Stakeholder Configurations}

Our understanding of algorithmic curation of urban experiences also needs to encompass an analysis of the curation logics, i.e., the logics behind the mechanisms that curate the information flows. Here, one should identify the different stakeholders involved and their corresponding interests and motivations. However, the specific group of stakeholders and their interaction typically depends on the specific case, and therefore we omit a detailed discussion here. On a general level, we identify the following stakeholder categories: End-users, the ones who receive the information, most often citizens in the urban context; providers, those who (indirectly) provide the data, e.g., retailers, points of interest or city administrations; service operators, the entity who operates the service in which the algorithms are embedded; and society, those who represent the stakes of society, i.e., the common good.

It is clear that these categories are non-exclusive and thus serve as a means to guide the identification of the stakeholders rather than a strict categorization. While the first three categories are in line with the categories previously identified in our discussion in Section 3.2, the fourth one has not yet been formulated explicitly. The societal impact of online algorithmic curation is most often considered as an aspect of the service operator itself (cf. discussions on accountability). However, in this case of the urban environment, we value the explicit modelling of this category as a separate one, because in public space there is the inherent involvement of city administrations and/or governments who have to safeguard the public interest, which might conflict with others' interests (Smets et al., 2020). The increased traffic in residential areas due to the use of Waze (Fisher, 2020) is again an example of such conflicting curational logics. While the end-user might indeed want to take the fastest route from point $A$ to $B$, from a societal point of view this might not be desired due to the resulting congestion or deterioration in small streets. At first sight, this might seem a mere practical issue in the sense that people lose time or roads should be maintained more frequently. However, this increased traffic also changes the safety and hence the social function of these streets. Whereas normally children can play on the streets, this will no longer be the case when the traffic increases. This not only affects the children, but also the parents who often get to know each other by getting out on the streets while their children play. This example clearly illustrates the complex interplay between the curation logics of multiple stakeholders and will be a crucial building block of the study of algorithmic curation.

\section{Towards an Integrative Approach}

We conclude this discussion by presenting an integrative framework (Figure 2) that illustrates the identified urban algorithmic mediators and information flows that might eventually alter the urban experience, thereby addressing our main research question. Our framework illustrates that there are multiple ways for algorithms to curate urban experiences, however, the actual relationships are much more complex compared to how they are depicted in Figure 2. As highlighted before, we should also take into account feedback loops: For example, citizens sharing their experiences on social media could provide data for urban digital twins (Mohammadi \& Taylor, 2020).

By breaking down the different steps from data to the urban experience, this framework allows to analyze the curation mechanisms (selecting, organizing, etc.) that act upon the information flows and thus structure the study of algorithmic curation of urban experiences. This framework not only allows to structure empirical research to investigate a particular phenomenon, but also to facilitate comparative research or study the normative aspects of algorithmic curation. The latter could for example relate to the formulation of particular normative principles for algorithmic systems, where the framework allows to investigate if and to what extent this principle should apply to different information flows or how it can be operationalized. 


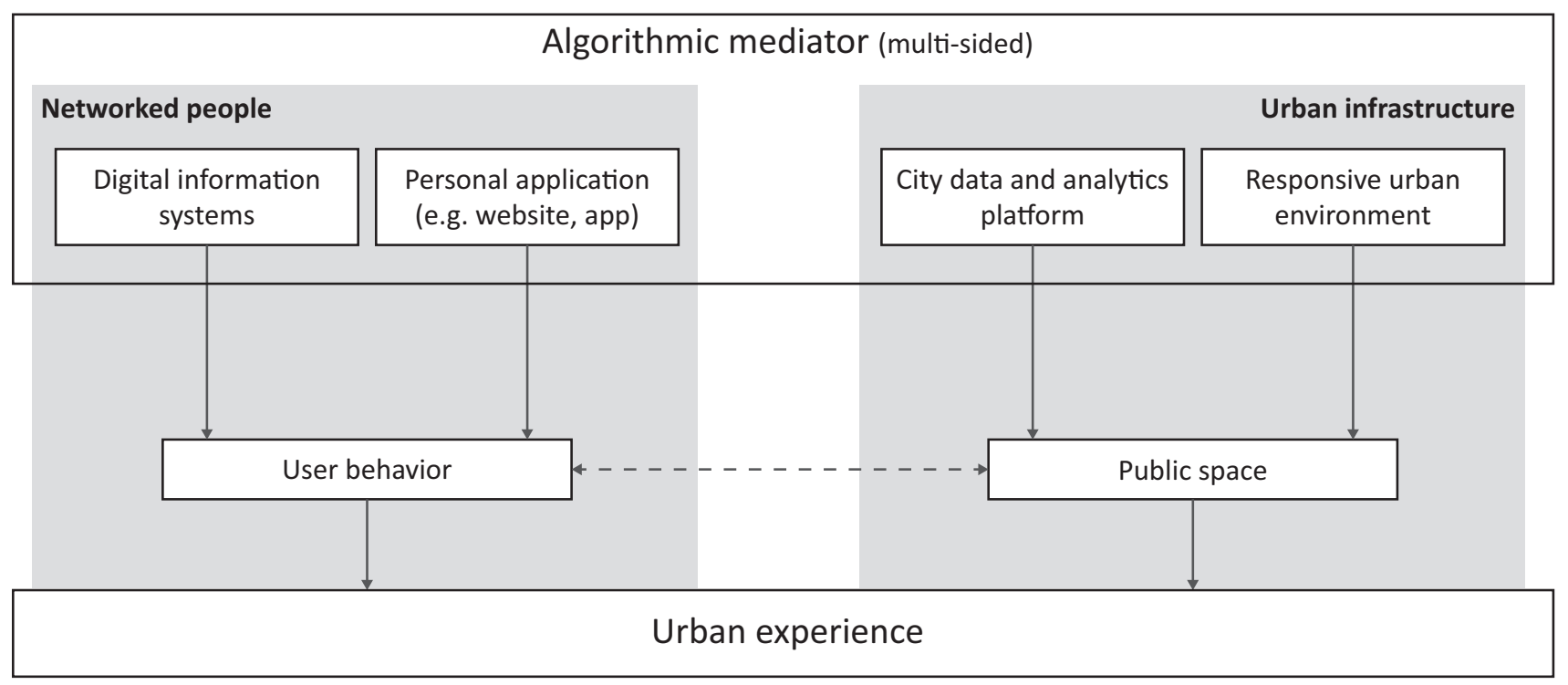

Figure 2. Framework on algorithmic curation of urban experiences.

The operationalization of the research would then require studying algorithms, which is known to be a difficult task. Different research methods have been suggested such as interviewing designers, reverse engineering, or examining pseudo-code (Kitchin, 2017b). We suggest that the study of these algorithms is accompanied by a stakeholder mapping in order to take into account the broader socio-technical setting. The stakeholder categories mentioned in the previous section can be used as a starting point to identify the specific stakeholders involved and how their interests define or influence the curation logics. Here, the most important question is to identify the overall strategic objectives of each actor and how these potentially result in incompatible or competing curation logics. There is also the possibility to conduct user studies looking closely into the citizens' experiences of these curational activities. To do so, there is a broad range of user research methodologies that already has been extensively used in urban contexts, such as surveys, focus groups or large-scale experimental designs often referred to as "living labs" (Ballon \& Schuurman, 2015).

\section{Conclusions}

This work originated from our interest in algorithmic curation in urban environments, and the observations that on the one hand, the current study of algorithmic curation lacks a foundation that takes into account the specific nature of the urban context, whereas, on the other hand, the smart city discourse that is particularly concerned with the interplay of digital technology and urbanism, fails to capture this curational aspect of algorithms. To address this shortcoming, we present an analytical approach to study algorithmic curation of urban experiences, building upon prior work in media and communication studies, and elaborated upon by means of case examples in the urban realm. More specifically, we identified urban algorithmic mediators, consisting of networked people and urban infrastructure, discussed the notion of urban curation logics, and categorized potential stakeholders. The latter can be used as a starting point to identify the specific stakeholders involved, and how their interests define or influence the curation practices.

The main limitation of this study is the degree to which each of the components in the framework is elaborated. Although we acknowledge this shortcoming, we believe that our work could serve as a starting point for extensions or adjustments based on further research. We acknowledge that the current framework is indeed just a conceptual one and would thus benefit from an empirical verification. Future work could address this by applying the framework to actual use cases. This will not only demonstrate its empirical value but also help to refine it. As such, the study at hand attempts to be a first valuable contribution to the critical study of algorithmic curation in urban contexts and remains open to empirical verification, extensions, and adjustments as more research in this field emerges.

In this way, we present a first approach towards the study of algorithmic curation in urban environments and more specifically the algorithmic curation of urban experiences. Our analysis indicates some similarities with algorithmic curation in online platforms. However, the physical characteristics of the urban environment require an adjusted approach to study algorithmic 
curation in the urban context. After all, algorithms can influence urban experiences without a direct technological interface towards the citizen, for example through the urban infrastructure. Moreover, a significant interaction effect exists between individual user behavior and the public space that can have complex (in)direct consequences. These findings illustrate that there is definitely a continuation of algorithmic curation from the online to the offline world, and that its study requires a full sociotechnical approach both in terms of actors and physical places. We believe that this framework can set the scene for further research in this field that not only considers the curational practices themselves, but also investigates related concepts and phenomena in more depth. For example, if and how citizens might develop strategies to "game the algorithm." Inspired by the German artist Simon Weckert (2020), who generated a virtual traffic jam in Google Maps by walking through a street with 99 mobile phones in a handcart, we could imagine that citizens adopt a similar hack to avoid Waze-users disturbing their quiet neighborhood. By extending the scope of algorithmic curation to the urban environment, we hope this work inspires other scholars to study phenomena that we know online, in the offline world as well.

\section{Acknowledgments}

We are particularly grateful to Rob Heyman for his contribution to an earlier version of this work. We also thank the anonymous reviewers whose suggestions helped to improve and clarify our manuscript.

\section{Conflict of Interests}

The authors declare no conflict of interests.

\section{References}

Abella, A., Ortiz-de-Urbina-Criado, M., \& De-PablosHeredero, C. (2017). A model for the analysis of data-driven innovation and value generation in smart cities' ecosystems. Cities, 64, 47-53. https://doi.org/ 10.1016/j.cities.2017.01.011

Al Nuaimi, E., Al Neyadi, H., Mohamed, N., \& Al-Jaroodi, J. (2015). Applications of big data to smart cities. Journal of Internet Services and Applications, 6(1), 25.

Amin, A., \& Thrift, N. (2002). Cities: Reimagining the urban. Polity Press.

Andreani, S., Kalchschmidt, M., Pinto, R., \& Sayegh, A. (2019). Reframing technologically enhanced urban scenarios: A design research model towards human centered smart cities. Technological Forecasting and Social Change, 142, 15-25.

Bagdikian, B. H. (1983). The media monopoly. Beacon Press.

Ballon, P., \& Schuurman, D. (2015). Living labs: Concepts, tools, and cases. Info, 17(4). https://doi.org/ 10.1108/info-04-2015-0024
Ballon, P., \& Smets, A. (2021). De slimme stad: Stedelijke dataficatie in theorie en praktijk [The smart city: Urban datafication in theory and practice]. In G-J. Hospers \& P. Renooy (Eds.), De Wereld van De Stad [The world of the city]. Berghauser Pont.

Bandy, J., \& Diakopoulos, N. (2019). Auditing news curation systems: A case study examining algorithmic and editorial logic in apple news. arXiv. https://arxiv.org/ abs/1908.00456

Bernal, P. (2018). Fakebook: Why Facebook makes the fake news problem inevitable. Northern Ireland Legal Quarterly, 69(4), 513-530.

Bilandzic, A., Casadevall, D., Foth, M., \& Hearn, G. (2018). Social and spatial precursors to innovation: The diversity advantage of the creative fringe. The Journal of Community Informatics, 14(1), 160-182. https://doi. org/10.15353/joci.v14i1.3408

Bucher, T. (2017). The algorithmic imaginary: Exploring the ordinary affects of Facebook algorithms. Information, Communication \& Society, 20(1), 30-44. https:// doi.org/10.1080/1369118X.2016.1154086

Bucher, T. (2018). If...Then: Algorithmic power and politics. Oxford University Press.

Cervantes, O., Gutiérrez, E., Gutiérrez, F., \& Sánchez, J. A. (2016). Social metrics applied to smart tourism. ISPRS Annals of the Photogrammetry, Remote Sensing and Spatial Information Sciences, 4(1), 117-124.

Cohen, J. N. (2018). Exploring echo-systems: How algorithms shape immersive media environments. Journal of Media Literacy Education, 10(2), 139-151.

De Meulenaere, J., Baccarne, B., Courtois, C., \& Ponnet, K. (2020). Disentangling social support mobilization via online neighborhood networks. Journal of Community Psychology, 49(2), 481-498. https://doi.org/ 10.1002/jcop.22474

de Waal, M. (2013). De stad als interface: Hoe nieuwe media de stad veranderen [The city as interface: How new media are changing the city]. Rotterdam.

Diakopoulos, N. (2015). Accountability in algorithmic decision-making. Queue, 13(9), 126-149.

Eslami, M., Karahalios, K., Sandvig, C., Vaccaro, K., Rickman, A., Hamilton, K., \& Kirlik, A. (2016). First I like it, then I hide it: Folk theories of social feeds. In J. Kaye \& A. Druin (Eds.), Proceedings of the $2016 \mathrm{CHI}$ conference on human factors in computing systems (pp. 2371-2382). ACM.

Eslami, M., Rickman, A., Vaccaro, K., Aleyasen, A., Vuong, A., Karahalios, K., Hamilton, K., \& Sandvig, C. (2015). I always assumed that I wasn't really that close to [her]: Reasoning about invisible algorithms in news feeds. In B. Begole \& J. Kim (Eds.), Proceedings of the 33rd annual ACM conference on human factors in computing systems (pp. 153-162). ACM.

Fisher, E. (2020). Do algorithms have a right to the city? Waze and algorithmic spatiality. Cultural Studies. Advance online publication. https://doi.org/ 10.1080/09502386.2020.1755711

Foth, M. (2017, June 26). The software-sorted city: Big 
data \& algorithms [Workshop paper]. Digital Cities 10 Workshop, Troyes, France.

Foth, M., Forlano, L., Satchell, C., \& Gibbs, M. (2011). Crowdsensing in the web: Analyzing the citizen experience in the urban space. In M. Foth, L. Forlano, C. Satchell, \& M. Gibbs (Eds.), From social butterfly to engaged citizen (pp. 353-373). MIT Press. https:// doi.org/10.7551/mitpress/8744.003.0029

Graham, S. D. N. (2005). Software-sorted geographies. Progress in Human Geography, 29(5), 562-580. https://doi.org/10.1191/0309132505ph568oa

Guda, H., \& Subramanian, U. (2019). Your Uber is arriving: Managing on-demand workers through surge pricing, forecast communication, and worker incentives. Management Science, 65(5), 1995-2014. https://doi. org/10.1287/mnsc.2018.3050

Hanzl, M., Dzik, K., Kowalczyk, P., Kwieciński, K., Stankiewicz, E., \& Wierzbicka, A. L. (2012). Human geomatics in urban design-Two case studies. Future Internet, 4(1), 347-361.

Jacobs, J. (1961). The death and life of great American cities. Vintage Books.

Kitchin, R. (2014). The real-time city? Big data and smart urbanism. GeoJournal, 79(1), 1-14. https://doi.org/ 10.1007/s10708-013-9516-8

Kitchin, R. (2017a). Data-driven urbanism. In R. Kitchin, T. P. Lauriault, \& G. McArdle (Eds.), Data and the city (1st ed., pp. 44-56). Routledge. https://doi.org/ 10.4324/9781315407388-4

Kitchin, R. (2017b). Thinking critically about and researching algorithms. Information, Communication \& Society, 20(1), 14-29. https://doi.org/ 10.1080/1369118X.2016.1154087

Kitchin, R., \& Dodge, M. (2011). Code/space: Software and everyday life. MIT Press.

Koto, Z., \& Bandung, Y. (2016). Interactive digital signage architecture to improve user interaction on tourism information services. In M. Amin Sulthoni (Ed.), 2016 international symposium on electronics and smart devices (ISESD) (pp. 380-385). IEEE. https://doi.org/ 10.1109/ISESD.2016.7886752

Ku, K. Y., Kong, Q., Song, Y., Deng, L., Kang, Y., \& Hu, A. (2019). What predicts adolescents' critical thinking about real-life news? The roles of social media news consumption and news media literacy. Thinking Skills and Creativity, 33, Article 100570. https:// doi.org/10.1016/j.tsc.2019.05.004

Landerer, N. (2013). Rethinking the logics: A conceptual framework for the mediatization of politics. Communication Theory, 23(3), 239-258. https://doi.org/ 10.1111/comt.12013

Lim, C., Kim, K.-J., \& Maglio, P. P. (2018). Smart cities with big data: Reference models, challenges, and considerations. Cities, 82, 86-99. https://doi.org/10.1016/ j.cities.2018.04.011

Liu, S. B. (2010). Trends in distributed curatorial technology to manage data deluge in a networked world. Upgrade: The European Journal for the Informatics
Professional, 11(4), 18-24.

Liu, S. B. (2012). The living heritage of historic crises: Curating the Bhopal disaster in the social media landscape. Interactions, 19(3), 20-24. https://doi.org/ $10.1145 / 2168931.2168938$

Macfarlane, J. (2019). When apps rule the road: The proliferation of navigation apps is causing traffic chaos. It's time to restore order. IEEE Spectrum, 56(10), 22-27.

Martín-Martín, A., Orduna-Malea, E., Thelwall, M., \& López-Cózar, E. D. (2018). Google Scholar, Web of Science, and Scopus: A systematic comparison of citations in 252 subject categories. Journal of Informetrics, 12(4), 1160-1177. https://doi.org/10.1016/j.joi. 2018.09.002

McQuire, S. (2016). Geomedia: Networked cities and the future of public space. Wiley.

McStay, A. (2016). Empathic media and advertising: Industry, policy, legal, and citizen perspectives (the case for intimacy). Big Data \& Society, 3(2). https:// doi.org/10.1177/2053951716666868

Mohammadi, N., \& Taylor, J. (2020). Knowledge discovery in smart city digital twins. In T. X. Bui (Ed.), Proceedings of the 53rd Hawaii international conference on system sciences (pp. 1656-1664). HICSS. http:// hdl.handle.net/10125/639439

Mohammadi, N., \& Taylor, J. E. (2017). Smart city digital twins. In P. Bonissone \& D. Fogel (Eds.), 2017 IEEE Symposium Series on Computational Intelligence (SSCl) (pp. 1-5). IEEE. https://doi.org/10.1109/SSCl. 2017.8285439

Mora, H., Gilart-Iglesias, V., Pérez-del Hoyo, R., \& Andújar-Montoya, M. (2017). A comprehensive system for monitoring urban accessibility in smart cities. Sensors, 17(8), 1834. https://doi.org/10.3390/ s17081834

Napoli, P. M. (2018). What social media platforms can learn from audience measurement: Lessons in the self-regulation of "black boxes". SSRN. http://dx.doi. org/10.2139/ssrn.3115916

Nelimarkka, M., Laaksonen, S.-M., \& Semaan, B. (2018). Social media is polarized, social media is polarized: Towards a new design agenda for mitigating polarization. In I. Koskinen \& Y.-K. Lim (Eds.), Proceedings of the 2018 on designing interactive systems conference 2018-DIS '18 (pp. 957-970). ACM. https://doi.org/ 10.1145/3196709.3196764

Prado, L. (2014). A protected life: Speculations on object-mediated relationships. In F. Paiva \& C. Moura (Eds.), DESIGNA 2013: Interface proceedings (p. 361). Ubi. https://labcom.ubi.pt/ficheiros/ 20140608-designa2013_proceedings_flat.pdf

Rader, E. (2017). Examining user surprise as a symptom of algorithmic filtering. International Journal of Human-Computer Studies, 98, 72-88.

Rader, E., \& Gray, R. (2015). Understanding user beliefs about algorithmic curation in the Facebook news feed. In B. Begole \& J. Kim (Eds.), Proceedings of the 33rd annual ACM conference on human factors 
in computing systems-CHI '15 (pp. 173-182). ACM. https://doi.org/10.1145/2702123.2702174

Ridell, S., \& Zeller, F. (2013). Mediated urbanism: Navigating an interdisciplinary terrain. SAGE.

Sandvig, C., Hamilton, K., Karahalios, K., \& Langbort, C. (2014). Auditing algorithms: Research methods for detecting discrimination on internet platforms. Data and discrimination: Converting Critical Concerns Into Productive Inquiry, 22, 4349-4357.

Seaver, N. (2019). Knowing algorithms. In J. Vertesi \& D. Ribes (Eds.), DigitalSTS: A field guide for science \& technology studies (pp. 412-422). Princeton University Press.

Sennett, R. (1978). The fall of public man: On the social psychology of capitalism. Vintage Books.

Shapiro, B. R., \& Hall, R. (2018). Personal curation in a museum. Proceedings of the ACM on HumanComputer Interaction, 2(CSCW), pp. 1-22. https:// doi.org/10.1145/3274427

Shoemaker, P. J., \& Vos, T. P. (2009). Gatekeeping theory. Routledge.

Smets, A., Montero, E., \& Ballon, P. (2019). Does the bubble go beyond? An exploration of the Urban filter bubble. In O. S. Shalom, D. Jannach, \& I. Guy (Eds.), Proceedings of the 1st workshop on the impact of recommender systems (pp. 1-6). CEUR. http://ceur-ws.org/ Vol-2462/paper3.pdf

Smets, A., Walravens, N., \& Ballon, P. (2020). Designing recommender systems for the common good. In T. Kuflik \& I. Torre (Eds.), Adjunct publication of the 28th ACM conference on user modeling, adaptation and personalization (pp. 276-278). ACM. https://doi.org/ $10.1145 / 3386392.3399570$
Swords, J. (2017). Crowd-patronage-Intermediaries, geographies, and relationships in patronage networks. Poetics, 64, 63-73.

Thorson, K., \& Wells, C. (2015a). Curated flows: A framework for mapping media exposure in the digital age. Communication Theory, 26(3), 309-328.

Thorson, K., \& Wells, C. (2015b). How gatekeeping still matters: Understanding media effects in an era of curated flows. In T. P. Vos \& F. Heinderyckx (Eds.), Gatekeeping in transition (pp. 39-58). Routledge.

Trielli, D., \& Diakopoulos, N. (2019). Search as news curator: The role of Google in shaping attention to news information. In S. Brewster \& G. Fitzpatrick (Eds.), Proceedings of the $2019 \mathrm{CHI}$ conference on human factors in computing systems (pp. 1-15). ACM. https:// doi.org/10.1145/3290605.3300683

Usher, N. (2017). Venture-backed news startups and the field of journalism: Challenges, changes, and consistencies. Digital Journalism, 5(9), 1116-1133.

Weckert, S. (2020). Google maps hacks: Performance \& installation, 2020. http://www.simonweckert.com/ googlemapshacks.html

Willson, M. (2017). Algorithms (and the) everyday. Information, Communication \& Society, 20(1), 137-150. https://doi.org/10.1080/1369118X.2016.1200645

Wohn, D. Y., \& Bowe, B. J. (2016). Micro agenda setters: The effect of social media on young adults' exposure to and attitude toward news. Social Media + Society, 2(1). https://doi.org/10.1177/2056305115626750

Yatid, M. M. (2019). Truth tampering through social media: Malaysia's approach in fighting disinformation \& misinformation. IKAT: The Indonesian Journal of Southeast Asian Studies, 2(2), 203-230.

\section{About the Authors}

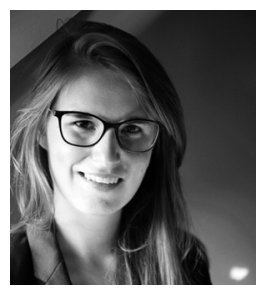

Annelien Smets is a doctoral researcher at imec-SMIT at the Vrije Universiteit Brussel. Her research interests include datafication and personalization in digital media and smart cities. Her doctoral research deals with the use of recommender systems in cities, with a particular focus on the value of serendipity.

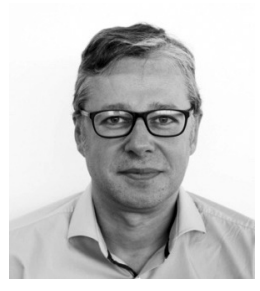

Pieter Ballon is full professor at the Department of Communication Studies at Vrije Universiteit Brussel where he teaches on media and internet economics. He is director of research group imec-SMIT. His research centers on the political economy of digital platforms in media, mobile, and urban contexts. He has published widely on these topics in peer-reviewed international journals.

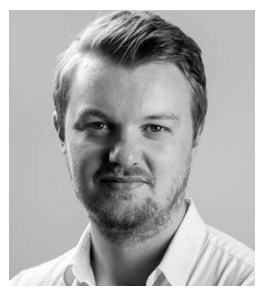

Nils Walravens graduated cum laude as master in communication sciences at the Vrije Universiteit Brussel in July 2007. He started working for imec-SMIT in August of 2007 as a researcher, developing expertise in the field of business modelling and policy research. In 2016, he defended his PhD on the topic of smart cities and public value, and has since worked as a senior researcher focusing on the topics of smart cities and open data at imec-SMIT. 